\title{
A prevalent mutation with founder effect in Spanish Recessive Dystrophic Epidermolysis Bullosa families
}

\author{
Natividad Cuadrado-Corrales ${ }^{1,2}$, Carolina Sánchez-Jimeno ${ }^{1,2}$, Marta García ${ }^{1,2}$, María-José Escámez ${ }^{1,2}$, Nuria Illera , \\ Ángela Hernández-Martín ${ }^{3}$, María-José Trujillo-Tiebas ${ }^{4,5}$, Carmen Ayuso ${ }^{4,5}$, Marcela Del Rio ${ }^{1,2^{*}}$
}

\begin{abstract}
Background: Recessive Dystrophic Epidermolysis Bullosa (RDEB) is a genodermatosis caused by more than 500 different mutations in the COL7A1 gene and characterized by blistering of the skin following a minimal friction or mechanical trauma.

The identification of a cluster of RDEB pedigrees carrying the c.6527ins C mutation in a specific area raises the question of the origin of this mutation from a common ancestor or as a result of a hotspot mutation. The aim of this study was to investigate the origin of the c.6527insC mutation.
\end{abstract}

Methods: Haplotypes were constructed by genotyping nine single nucleotides polymorphisms (SNPS) throughout the COL7A1 gene. Haplotypes were determined in RDEB patients and control samples, both of Spanish origin.

Results: Sixteen different haplotypes were identified in our study. A single haplotype cosegregated with the c.6527insC mutation.

Conclusion: Haplotype analysis showed that all alleles carrying the c.6527insC mutation shared the same haplotype cosegregating with this mutation (CCGCTCAAA_6527ins $C$ ), thus suggesting the presence of a common ancestor.

\section{Background}

Dystrophic Epidermolysis Bullosa (DEB) is a rare disease, characterized by trauma induced-blistering and scarring [1]. This genodermatosis is a rare autosomal dominant (DDEB [MIM\#131750, \#131800]) or recessive (RDEB [MIM\#226600]) disorder caused by mutations in COL7A1 gene [MIM*120120], encoding type VII collagen (protein component of anchoring fibrils) [2]. COL7A1 gene is an unusually complex gene with 118 exons. It has the second largest number of exons of all genes described to date [3]. So far, more than 500 mutations have been described in the COL7A1 gene http://www.hgmd.cf.ac.uk [4]. Although COL7A1 genetic database indicates that most of the DEB mutations are family specific, with few recurrent mutations, in the Spanish cohort, a high recurrence of the c.6527ins $C$ pathogenic mutation has recently been

\footnotetext{
* Correspondence: marcela.delrio@ciemat.es

'Basic Research Department, Epithelial Biomedicine Division, Regenerative Medicine Unit, CIEMAT, Madrid, Spain

Full list of author information is available at the end of the article
}

reported by our group [5]. Accounting for $46.3 \%$ of alleles this is a level of recurrence for a single genetic defect hardly ever found for the COL7A1 gene [5,6]. The c.6527insC mutation creates a premature codon termination (PTC), leading to nonsense mediated decay (NMD) that manifests as a complete absence of collagen protein (Fig. 1). This insertion mutation was detected mainly in families native of the southwest of the Iberian Peninsula (Fig. 2). The overrepresentation of a single mutation and the geographic clustering of the c.6527insC pedigrees indicate at least one founder effect or a mutational hotspot. We investigated the putative founder effect of the c.6527insC mutation through the construction of SNP haplotypes throughout the COL7A1 gene. A rare single haplotype in the Spanish population was present in all patients and relatives who carried the c.6527insC mutation, supporting the hypothesis that all chromosomes carrying the c.6527insC mutation arise from a single founder effect. 


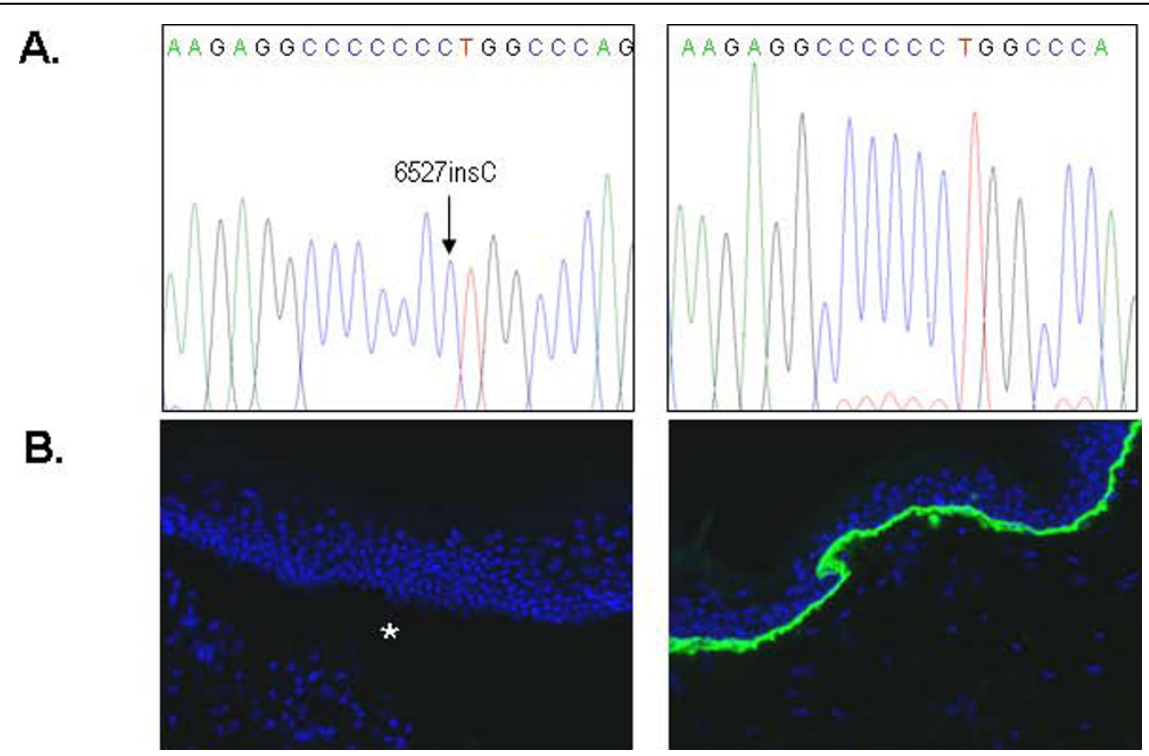

Figure 1 Molecular and microscopic characterization of RDEB patients that are homozygotes for c.6527insC in exon 80. (A) Identification of the c.6527insC mutation by direct DNA sequence analysis. The chromatogram shows the pattern of $7 \mathrm{C}$ peaks typically found in these patients (left) when compared with healthy controls (right). (B) Indirect immunofluorescent staining with LH7.2 monoclonal antibody (NC-1 domain of type VII collagen). The control section shows a continuous staining along the intact dermal-epidermal junction (right), while the section from the patient is negative to the staining and show a dermal-epidermal cleavage $\left(^{*}\right)$.

\section{Methods}

\section{Subjects}

A total of 49 DEB patients were included in this study. Patient written informed consent was obtained in agreement with the collaborative centers where biopsies and

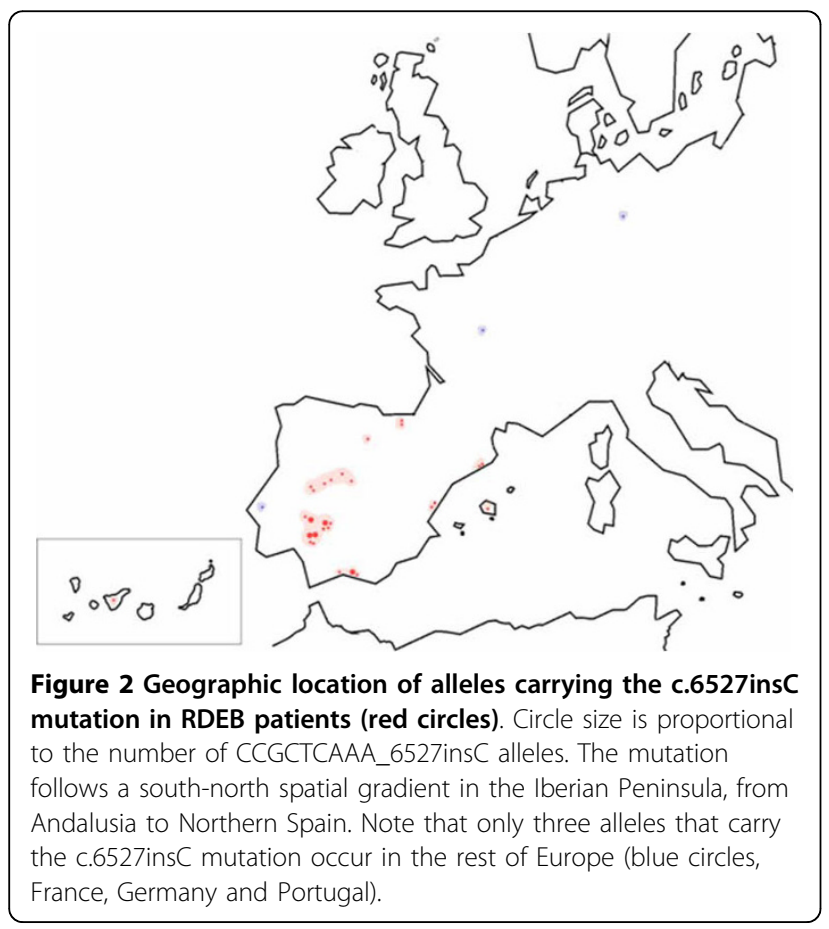

blood/DNA samples were obtained. The Ethics Committee of Fundación Jimenez Díaz (Madrid, Spain) evaluated and approved this research work, stating that the project adheres to the Helsinki Guidelines and further reviews (Edinburgh, 2000; http://www.wma.net).

Eleven RDEB patients carried the c.6527insC mutation in both alleles. Sixteen RDEB patients were heterozygote, exhibited the c.6527ins $\mathrm{C}$ mutation on one allele and contained different mutations on the other allele. Twenty two DEB patients carried other mutations of the COL7A1 gene (Additional file 1, Table S1). In addition, 93 non-affected individuals from the general population of Spain were incorporated to this study as a reference group. Informed consent was obtained from all subjects included in the study. Putative geographic origin of pedigrees was empirically established based on proof that individuals carrying this mutation stem from ancestors who have lived in the same geographic area for at least 3 generations.

\section{SNPs selection and haplotyping assay}

We used the HapMap data http://www.hapmap.org to select informative SNPs from the COL7A1 gene. Using the Haploview program, two blocks of linkage disequilibrium (LD) are located throughout the COL7A1 gene (Fig. 3). Two SNPs (rs2228561 and rs1264194) from block 1 and five SNPs (rs9881877, rs9871180, rs9814951, rs9878950 and rs2532848) from block 2 were analyzed to determine common haplotypes according to the 


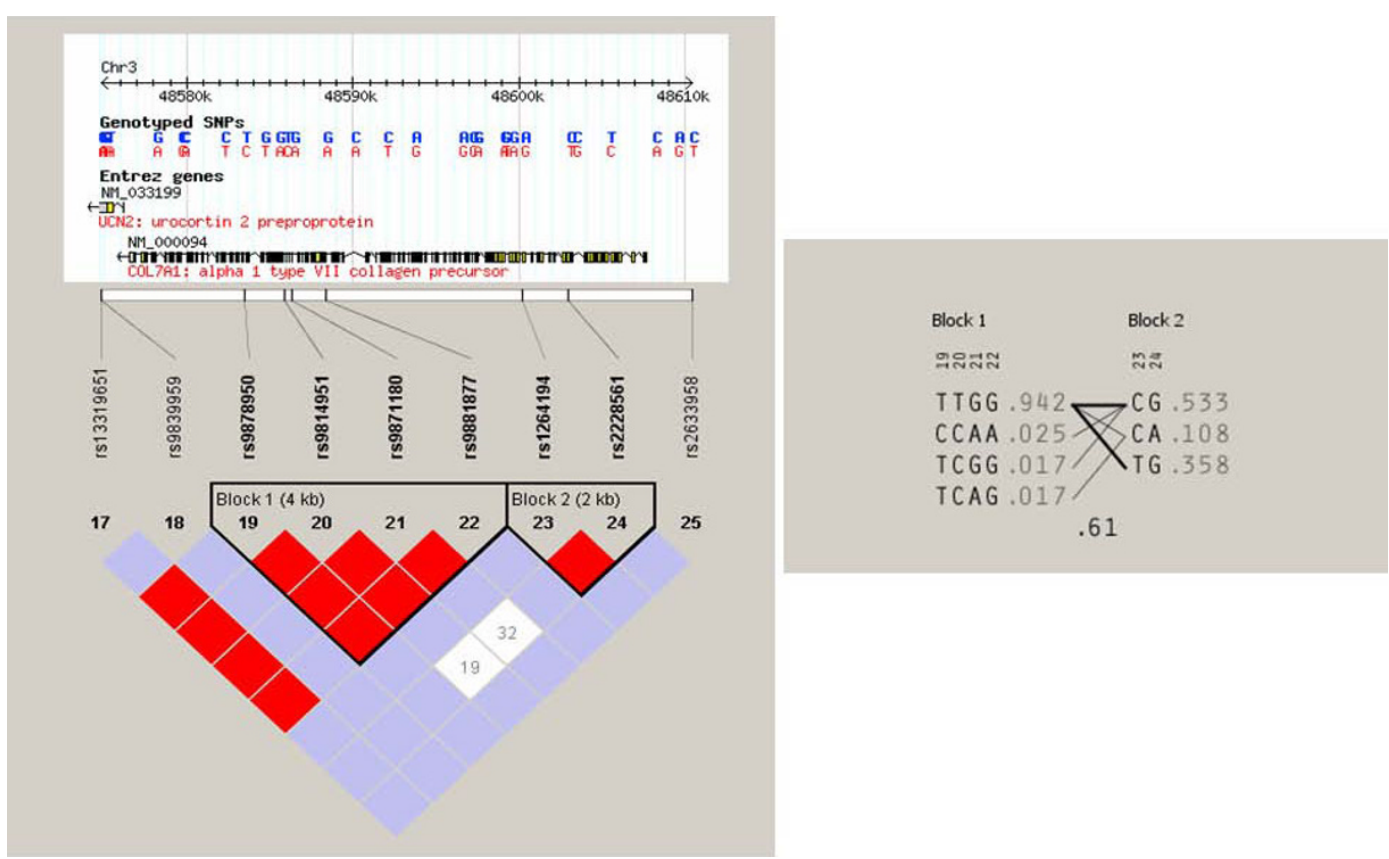

Figure 3 Haplotype structure of the COL7A1 gene locus in Europeans. (A) Structure of the COL7A1 gene with positions of SNPs by the Hap Map project. Haploview-generated linkage disequilibrium (LD) patterns of the COL7A1 gene and predicted block structure in Caucasian control subjects. Rate ( $\left.D^{\prime}\right)$ of $L D$ is represented by different colors (highest rate of LD in red, lower LD in purple, and white for no LD). (B) Potential haplotypes in the European population for six selected SNPs that have been genotyped in our study.

Hap-Map data. We also included in the analysis two novel polymorphisms, NM-000094.3:c.25215C > T (intron 75) and NM-000094.3:c.11639C > T (intron 19) recognized in the Spanish population.

Haplotypes for chromosomes harboring the c.6527insC mutation and other mutations were determined by genotyping SNPs for DEB patients and their parents (Fig. 4).

The genotyping of SNPs was performed with Snapshot assay kits (Applied Biosystems Inc.). Amplicons were purified by Exo-SAP treatment (ExoSAP-IT, USB). Three $\mu \mathrm{l}$ aliquots of the purified amplification products were added to a $5 \mu \mathrm{l}$ Snapshot Multiplex Ready reaction mixture containing $0.4 \mathrm{pmol}$ of each Snapshot oligonucleotide primers (Additional file 1, Table S2). Primer extension reactions were carried out over 25 cycles of $96^{\circ} \mathrm{C}$ for $10 \mathrm{sec}, 50^{\circ} \mathrm{C}$ for $5 \mathrm{sec}$, and $60^{\circ} \mathrm{C}$ for $30 \mathrm{sec}$. Reaction products were treated with $1 \mathrm{U}$ of SAP at $37^{\circ} \mathrm{C}$ for $1 \mathrm{~h}$ and $72^{\circ} \mathrm{C}$ for $15 \mathrm{~min}$ to dephosphorylate unincorporated fluorescent ddNTPs. The Snapshot reactions were resolved on an ABI Prism 3730 (Applied Biosystems). Results were analyzed using Peak Scanner ${ }^{\mathrm{Tm}}$ Software v1.0 (Applied Biosystems).

\section{Statistical analysis}

We evaluated the Hardy-Weinberg Equilibrium (HWE) distributions, in a control sample from the general population of Spain, for the SNPs involved in our study.

\section{Results}

We identified 5 novel SNPs in the region corresponding to COL7A1 gene, NM-000094.3:c.11639C > T, 24558C > T, $25215 \mathrm{C}>\mathrm{T}, 29056 \mathrm{C}>\mathrm{T}, 31427 \mathrm{C}>\mathrm{A}$. The distribution of all SNPs in the control Spanish population did not deviate from HWE (?2-test; p > 0.05) (Additional file 1, Table S3). The NM-000094.3:c.11639C $>\mathrm{T}$ and 25215C $>\mathrm{T}$ were considered for the construction of haplotypes.

The existence of complete two-generation pedigrees in all our patients allowed the construction of different haplotypes formed by nine SNPs. Considering the two blocks of linkage LD located throughout the COL7A1 gene, we determined twelve haplotypes in DEB patients (from $\mathrm{H} 1$ haplotype to $\mathrm{H} 7$ haplotype, H9, H12, H14, H15 and H16 haplotypes) and thirteen haplotypes in the Spanish population (from $\mathrm{H} 1$ to $\mathrm{H} 13$ ). The overall distribution of the estimated haplotypes was significantly different between healthy controls and patients (see Table 1 and Table 2).

The total number of the alleles $(n=38)$ that carry the c.6527ins C mutation cosegregated exclusively with $\mathrm{H} 5$ haplotype (CCGCTCAAA), namely all alleles that carry the c.6527insC mutation were CCGCTCAAA_6527insC. On the other hand, the frequency of $\mathrm{H} 5$ haplotype in the Spanish population was $5.81 \%$. Consequently, the c.6527insC mutation in the Spanish cluster is a result of a single mutational event, and the affected pedigrees must descend from one genetic founder who exhibited the H5 


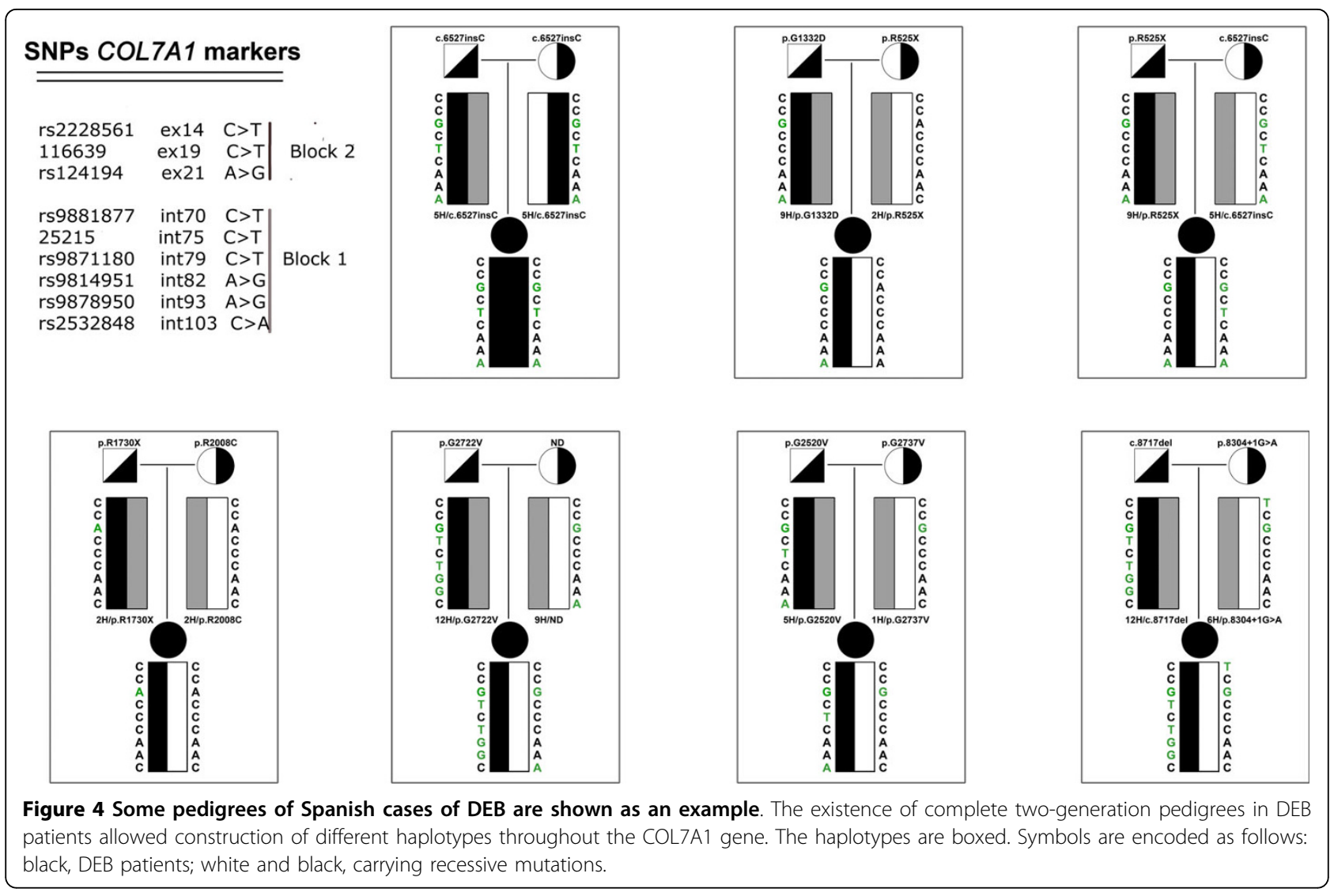

Table 1 The total number of haplotypes described in the Spanish population

\begin{tabular}{|c|c|c|c|c|c|c|c|c|c|c|}
\hline \multirow[b]{2}{*}{ Haplotypes } & \multicolumn{3}{|c|}{ Block 2} & \multicolumn{6}{|c|}{ Block 1} & \multirow[b]{2}{*}{$\begin{array}{c}\text { Haplotype } \\
\text { frequency } \\
\%\end{array}$} \\
\hline & $\mathrm{rs} 2228561$ & $\begin{array}{c}11639 \\
C>T\end{array}$ & rs1264194 & rs9881877 & $25215 C>T$ & rs9871180 & rs9814951 & rs9878950 & rs2532848 & \\
\hline$\overline{\mathrm{H} 1}$ & C & $C$ & $G$ & C & $C$ & $C$ & $A$ & $A$ & C & 33.7 \\
\hline $\mathrm{H} 2$ & C & C & A & C & C & C & A & A & C & 17.44 \\
\hline $\mathrm{H} 3$ & C & C & A & C & C & C & G & G & C & 10.46 \\
\hline $\mathrm{H} 4$ & C & $C$ & G & C & C & C & A & G & C & 5.81 \\
\hline $\mathrm{H} 5$ & C & C & G & C & $\mathrm{T}$ & C & A & A & A & 5.81 \\
\hline $\mathrm{H} 6$ & $\mathrm{~T}$ & $C$ & G & C & C & C & A & A & C & 4.65 \\
\hline $\mathrm{H} 7$ & C & C & G & $\mathrm{T}$ & C & C & A & A & C & 4.65 \\
\hline $\mathrm{H} 8$ & C & C & G & $C$ & C & $C$ & G & G & C & 4.65 \\
\hline $\mathrm{H} 9$ & C & C & G & C & C & C & A & A & A & 3.49 \\
\hline $\mathrm{H} 10$ & C & C & G & C & $\mathrm{T}$ & C & A & A & C & 3.49 \\
\hline $\mathrm{H} 11$ & C & - & A & C & C & C & A & G & C & 3.49 \\
\hline $\mathrm{H} 12$ & C & C & G & $\mathrm{T}$ & C & $\mathrm{T}$ & G & G & C & 1.16 \\
\hline $\mathrm{H} 13$ & C & - & A & C & $\mathrm{T}$ & C & A & A & C & 1.16 \\
\hline $\mathrm{H} 14$ & C & $\mathrm{T}$ & G & C & $\mathrm{T}$ & C & A & A & A & 0 \\
\hline $\mathrm{H} 15$ & C & $\mathrm{T}$ & $G$ & C & $\mathrm{T}$ & C & A & $G$ & A & 0 \\
\hline $\mathrm{H} 16$ & C & $\mathrm{T}$ & $G$ & C & C & C & A & A & C & 0 \\
\hline
\end{tabular}


Table 2 The total number of haplotypes described in DEB Spanish patients

\begin{tabular}{|c|c|c|c|c|c|c|c|c|c|c|}
\hline \multirow[b]{2}{*}{ Haplotypes } & \multirow[b]{2}{*}{$\begin{array}{l}\text { Mutation COL7A1 } \\
\text { gene }\end{array}$} & \multicolumn{3}{|c|}{ Block 2} & \multicolumn{6}{|c|}{ Block 1} \\
\hline & & rs2228561 & $\begin{array}{c}11639 \\
C>T\end{array}$ & rs1264194 & rs9881877 & $25215 C>T$ & rs9871180 & rs9814951 & rs9878950 & rs2532848 \\
\hline $\mathrm{H} 1$ & $\begin{array}{l}\text { p.Y112X (1), p.R185X } \\
\text { (2), p.G1318R (1), } \\
\text { p.G1791E (1), p.R1814C } \\
\text { (1), p.G2061V (1), } \\
\text { p.G2061V (1), p. } \\
\text { R2424W (1), p.G2587 D } \\
\text { (1), } \\
\text { p.R2622W(1), p.2737V } \\
\text { (1), c.267-3C>G (2), } \\
\text { c.4401+1G>A(1), } \\
\text { c.7420A }>G(1), c .7930- \\
1 G>C(3), \\
\text { c.7930+2T>C, } \\
\text { c.7756insC. }\end{array}$ & $C$ & $C$ & $\mathrm{G}$ & $C$ & $C$ & $C$ & $\mathrm{~A}$ & $A$ & $C$ \\
\hline $\mathrm{H} 2$ & $\begin{array}{l}\text { p.R525X (1), p.R1730X } \\
\text { (1), p.R2063W (1), } \\
\text { c.7104+5G }>\text { A (1), } \\
\text { c.5576delAA (1), } \\
\text { c.325insGC (2), }\end{array}$ & C & C & A & C & C & C & A & A & C \\
\hline $\mathrm{H} 3$ & $\begin{array}{l}\text { p.G2434R (1), p.R2808C } \\
\text { (1) }\end{array}$ & $C$ & C & A & C & $C$ & C & G & G & $C$ \\
\hline $\mathrm{H} 4$ & c.58del13 (1) & C & C & G & C & C & C & A & G & C \\
\hline H5 & $\begin{array}{l}\text { c.6527insC (38), p. } \\
\text { G2520V (1) }\end{array}$ & C & C & G & C & $\mathbf{T}$ & C & A & A & A \\
\hline H6 & $\begin{array}{l}\text { p.Y1098X (2), } \\
\text { c.2781InsACGAC (1), } \\
\text { c.8304+1G>A (1) } \\
\end{array}$ & $\mathrm{T}$ & C & G & C & $C$ & C & A & A & $C$ \\
\hline $\mathrm{H} 7$ & $\begin{array}{l}\text { p.G2366 D (1), p.G2114 } \\
\text { D (1) }\end{array}$ & C & C & G & $\mathrm{T}$ & C & C & A & A & C \\
\hline $\mathrm{H} 8$ & - & C & C & G & C & C & C & G & G & C \\
\hline $\mathrm{H} 9$ & $\begin{array}{l}\text { p.G1332 D (1), c.R525X } \\
\text { (1), ND(1) }\end{array}$ & C & C & G & C & C & C & A & A & A \\
\hline $\mathrm{H} 10$ & - & C & C & G & C & $\mathrm{T}$ & C & A & A & C \\
\hline $\mathrm{H} 11$ & - & C & - & A & C & C & C & A & G & C \\
\hline $\mathrm{H} 12$ & $\begin{array}{l}\text { p.G2722V, c.8717delC } \\
\text { (1), ND (1). }\end{array}$ & C & C & G & $\mathrm{T}$ & C & $\mathrm{T}$ & G & G & C \\
\hline $\mathrm{H} 13$ & - & C & $\mathrm{T}$ & A & C & $\mathrm{T}$ & C & $A$ & A & C \\
\hline $\mathrm{H} 14$ & $\begin{array}{l}\text { C.5131nsCTCAC (2), } \\
\text { c.3277-1G>C (1) }\end{array}$ & C & $\mathrm{T}$ & G & C & $\mathrm{T}$ & C & A & A & A \\
\hline $\mathrm{H} 15$ & $\mathrm{ND}(2)$ & C & $\mathrm{T}$ & G & C & $\mathrm{T}$ & C & A & G & A \\
\hline $\mathrm{H} 16$ & C.7929+2T>C (1) & C & $\mathrm{T}$ & G & C & C & C & A & A & C \\
\hline
\end{tabular}

haplotype. Out of 27 pedigrees bearing at least one CCGCTCAAA_6527insC allele, 26 stemmed from ancestors who had been living in the southern half of the Iberian Peninsula for at least 3 generations. The other lineage bearing the CCGCTCAAA_6527insC allele comes from ancestors who had been living in Northern Spain for over 3 generations. In addition, we analyzed a Portuguese pedigree carrier of the CCGCTCAAA_6527insC allele. These results reveal that the $c .6527$ ins $C$ mutation is not the result of separate mutations occurring independently in different individuals, but is the result of a one-time mutation occurring in a common ancestor of all the families.
Furthermore, we also found a pedigree where the chromosome carrying the mutation cosegregated with G2520V $\mathrm{H} 5$ haplotype. The other forty recessive pathogenic mutations cosegregate with other fifteen different haplotypes (Table 2).

\section{Discussion}

High carrier rates are usually attributed to a founder effect in a population and are usually evidenced by conservation of haplotypes with directly associated markers [7]. We constructed fifteen different intragenic haplotypes throughout the COL7A1 gene to explore the origin of the 
alleles carrying the c.6527insC mutation and other mutations described in our DEB patients. All alleles carrying the c.6527insC mutation were CCGCTCAAA_6527insC, indicating a common origin. This hypothesis is supported by the diversity of haplotypes throughout the COL7A1 gene. Moreover, $\mathrm{H} 5$ haplotype is rare in the control population (5.81\%).

The c.6527ins C mutation is found at a high prevalence among patients from the southern half of the Iberian Peninsula. This mutation has previously been found in one patient in France [8] and in another in Germany [9]. However, a Spanish predecessor of those patients cannot be excluded, taking into account the large Spanish emigration to France that occurred after the Spanish civil war (1936-1939) and to Germany in the early 1960 s due to economic hard-ship.

The overall distribution of the estimated haplotypes was significantly different between patients and healthy controls. The absence of recurrence in the other mutations did not allow us to distinguish whether a single haplotype is associated with a mutation, or conversely, if one mutation is associated with general haplotypes suggesting multiple origins. The $\mathrm{H} 1$ and $\mathrm{H} 2$ haplotypes identified as cosegregating with other mutations are common in the background population. This finding is neither surprising nor unexpected. In terms of elementary probability, the probability of occurrence of a pathogenic mutation in a chromosome harboring a relatively common haplotype in the population is obviously high.

We found a single mutation, p.R525X, which cosegregated with two different haplotypes ( $\mathrm{H} 2$ haplotype and H9 haplotype). Moreover this nonsense mutation has been described previously in other DEB patient cohorts [10]. This could indicate the presence of a mutational hotspot in codon 525 of COL7A1 gene. Codon 525 contains a CpG dinucleotide, which is the known site of DNA modification by cytosine methylation.

\section{Conclusion}

In summary, the conservation of a single haplotype surrounding the c.6527ins $C$ mutation suggested that this allele has a single origin. The finding of a founder effect in a highly recurrent mutation in a rare disease characterized by intrafamilial mutations is essential for the implementation of protocols for genetic diagnosis, for genetic counselling of affected pedigrees and is fundamental to search for new therapies.

\section{Additional material}

Aditional file 1: Supplementary tables. Table S1. Summary of DEB Spanish patients included in this study. Table S2. Primer sequences used for Analysis of SNPS throughout the COL7A1 gene and primers used for SNaPshot. Table S3. Novel COL7A1 SNPs recognized in the present study.

\section{Acknowledgements}

The authors are indebted to the patients and their families who participated in this study for their constant support and motivation. We also thank all the clinicians and nurses involved. Our special thanks to DEBRA Spain for their continuous help.

This work was supported in part by grants from Spanish Ministry of Science and Innovation (SAF2007-61019 and SAF2010-16976) and INTRA/08/714 from Centro de Investigaciones Biomédicas en Red de Enfermedades Raras (CIBERER).

\section{Author details}

${ }^{1}$ Basic Research Department, Epithelial Biomedicine Division, Regenerative Medicine Unit, CIEMAT, Madrid, Spain. ${ }^{2}$ Centro de Investigaciones Biomédicas en Red de Enfermedades Raras (CIBERER- U714), Madrid, Spain. ${ }^{3}$ Department of Dermatology, Hospital Niño Jesús, Madrid, Spain. ${ }^{4}$ Department of Genetics, Fundación Jiménez Díaz, Madrid, Spain. ${ }^{5}$ Centro de Investigaciones Biomédicas en Red de Enfermedades Raras (CIBERER- U704), Madrid, Spain.

\section{Authors' contributions}

NCC drafted the manuscript and conceived and designed the study concept. MDR coordinated the analysis and interpretation of data and was responsible for final approval of the article. CSJ, MG and NI performed and assembly the molecular data, MJE contributed to the collection and assembly of clinical data and the statistical analysis. AHM performed the dermatological examinations. MJTT and CA provided critical revision of the manuscript.

All authors read and approved the final manuscript.

\section{Competing interests}

The authors declare that they have no competing interests.

Received: 1 June 2010 Accepted: 29 September 2010

Published: 29 September 2010

\section{References}

1. Fine JD, Eady RA, Bauer EA, Bauer JW, Bruckner-Tuderman L, Heagerty A, Hovnanian A, Jonkman MF, Leigh I, McGrath JA, Mellerio JE, Murrell DF, Uitto J, Vahlquist A, Woodley D, Zambruno G: The classification of inherited epidermolysis bullosa (EB): Report of the Third International Consensus Meetingon Diagnosis and Classification of EB. J Am Acad Dermatol 2008, 58:931-50.

2. Christiano AM, Hoffman GG, Chung-Honet LC, Lee S, Cheng W, Uitto J, Greenspan DS: Structural organization of the human type VII collagen gene (COL7A1) composed of more exons than any previously characterized gene. Genomics 1994, 21:169-79.

3. Strachan T, Read AP: Human molecular genetics Garland Science, New York, 32004.

4. Kern JS, Grüninger G, Imsak R, Müller ML, Schumann H, Kiritsi D, Emmert S, Borozdin W, Kohlhase J, Bruckner-Tuderman L, Has C: Forty-two novel COL7A1 mutations and the role of a frequent single nucleotide polymorphism in the MMP1 promoter in modulation of disease severity in a large European dystrophic Epidermolysis Bullosa cohort. $\mathrm{Br} J$ Dermatol 2009, 161:1089-1097.

5. Escámez MJ, García M, Cuadrado-Corrales N, Llames SG, Charlesworth A, De Luca N, Illera N, Sánchez-Jimeno C, Holguín A, Duarte B, Trujillo-Tiebas MJ, Santiago JL, Hernández-Martín A, Torrelo A, Castiglia D, Ayuso C, Larcher F, Jorcano JL, Meana A, Meneguzzi G, Zambruno G, Del Rio M: The first COL7A1mutation survey in a large Spanish dystrophic epidermolysis bullosa cohort: c.6527insC disclosed as an unusually recurrent mutation. Br J Dermatol 2010, 163:155-161.

6. Csikós M, Szocs HI, Lászik A, Mecklenbeck S, Horváth A, Kárpáti S, BrucknerTuderman L: High frequency of the $425 \mathrm{~A}->\mathrm{G}$ splice-site mutation and novel mutations of the COL7A1 gene in central Europe: significance for future mutation detection strategies in dystrophic epidermolysis bullosa. Br J Dermatol 2005, 152:879-886.

7. Morell RJ, Kim HJ, Hood LJ, Goforth L, Friderici K, Fisher R, Van Camp G, Berlin Cl, Oddoux C, Ostrer H, Keats B, Friedman TB: Mutations in the connexin 26 gene (GJB2) among Ashkenazi Jews with nonsyndromic recessive deafness. $N$ Engl J Med 1998, 339:1500-1505. 
8. Hovnanian A, Rochat A, Bodemer C, Petit E, Rivers CA, Prost C, Fraitag S, Christiano AM, Uitto J, Lathrop M, Barrandon Y, de Prost Y: Characterization of 18 new mutations in COL7A1 in recessive dystrophic Epidermolysis Bullosa provides evidence for distinct molecular mechanisms underlying defective anchoring fibril formation. Am J Hum Genet 1997, 61:599-610.

9. Kern JS, Kohlhase J, Bruckner-Tuderman L, Has C: Expanding the COL7A1 mutation database: novel and recurrent mutations and unusual genotype-phenotype constellations in 41 patients with dystrophic epidermolysis bullosa. J Invest Dermatol 2006, 126:1006-1012.

10. Whittock NV, Ashton GH, Mohammedi R, Mellerio JE, Mathew CG, Abbs SJ, Eady RA, McGrath JA: Comparative mutation detection screening of the type VII collagen gene (COL7A1) using the protein truncation test, fluorescent chemical cleavage of mismatch, and conformation sensitive gel electrophoresis. J Invest Dermatol 1999, 113:673-86.

Pre-publication history

The pre-publication history for this paper can be accessed here: http://www.biomedcentral.com/1471-2350/11/139/prepub

doi:10.1186/1471-2350-11-139

Cite this article as: Cuadrado-Corrales et al.: A prevalent mutation with founder effect in Spanish Recessive Dystrophic Epidermolysis Bullosa families. BMC Medical Genetics 2010 11:139.

\section{Submit your next manuscript to BioMed Central and take full advantage of:}

- Convenient online submission

- Thorough peer review

- No space constraints or color figure charges

- Immediate publication on acceptance

- Inclusion in PubMed, CAS, Scopus and Google Scholar

- Research which is freely available for redistribution

Submit your manuscript at www.biomedcentral.com/submit 